\title{
DISTANCIAS DE SIEMBRA Y COMBATE DE MALEZAS EN PEJIBAYE (Bactris gasipaes K) PARA PALMITO: EFECTO EN EL SUELO Y ARTRÓPODOS 1
}

\author{
Antonio Bogantes Arias ${ }^{2}$, Renán Agüero Alvarado ${ }^{3}$, Ramón Mexzón Vargas ${ }^{4}$
}

\begin{abstract}
RESUMEN
Distancias de siembra y combate de malezas en pejibaye (Bactris gasipaes $\mathrm{K}$.) para palmito: efecto en el suelo y artrópodos. En la Estación Experimental Los Diamantes, ubicada en Guápiles, Costa Rica, se evaluó, entre los años 2000 y 2001, el efecto de cuatro distancias de siembra entre plantas y dos estrategias de control de malezas, sobre variables químicas y microbiológicas del suelo, población de insectos y malezas, asociados al cultivo de pejibaye para palmito. No se observaron diferencias entre tratamientos con respecto a los nutrimentos del suelo, con excepción de una mayor cantidad de $\mathrm{K}$ en las parcelas con combate físico en el segundo muestreo. Hubo cambios entre muestreos para variables como el $\mathrm{pH}, \mathrm{Al}$ y $\mathrm{Ca}$. En el segundo muestreo las cantidades de hongos, bacterias y actinos en el suelo, fueron diferentes entre tratamientos. En un bloque adicional de parcelas de palmito con malezas, se recolectaron un total de 65 familias de insectos. Hubo aumentos importantes en el número de morfoespecies y de individuos entre el primero y segundo muestreo en familias de insectos; el mayor incremento en el número de familias, morfoespecies y número de individuos se dio en las parcelas sembradas a $0,25 \mathrm{~m}$ entre plantas.
\end{abstract}

Palabras clave: Bactris gasipaes, palmito, distancias, microorganismos, artrópodos.

\begin{abstract}
Weeds control in peach palm (Bactris gasipaes K.) for palm hearts: effect on soil and arthropods. A study was conducted at Los Diamantes Experiment Station, located in Guápiles, Costa Rica during the 2000 and 2001 year, to compare the effects of four sowing densities of spineless "palmito" peachpalm and two weed management strategies (chemical and physical) on chemical and microbiological characteristics of the soil, insect and weed populations in this crop. No differences were observed among treatments in regard to soil nutriments, except for a larger quantity of $\mathrm{K}$ in the plots subjected to physical treatment in the second sampling. Changes among samplings (first an second) were evident for variables such as the $\mathrm{pH}, \mathrm{Al}$ and $\mathrm{Ca}$. In the second sampling the quantities of fungi, bacteria and actynomycetes in the soil, were different among treatments. In additional plots with overgrowth, a total of 65 families of insects were gathered. There were important increases in the number of morphospecies and of individuals between the first one and second sampling in families of insects; the largest increment in the number of families, morphospecies and number of individuals was found in plots sowed with $0,25 \mathrm{~m}$ distance among plants.
\end{abstract}

Key words: Bactris gasipaes, palm hearts, densities, weeds, microorganisms, arthropods.

\section{INTRODUCCIÓN}

En un cultivo, una nueva variedad, obliga a implementar o ajustar técnicas de producción que complementen las bondades del mismo. En pejibaye se tiene al menos un nuevo material sin espinas con gran potencial para producción de palmito (Mora et al. 1999). La ausencia de espinas brinda nuevas oportunidades de

1 Recibido: 23 de febrero, 2005. Aceptado: 2 de febrero, 2006.

2 Estación Experimental Los Diamantes, Instituto Nacional de Innovación y Transferencia en Tecnología Agropecuaria - Ministerio de Agricultura y Ganadería (INTA - MAG). Costa Rica. Correo electrónico: bogantesa@ costarricense.cr

3 Facultad de Ciencias Agroalimentarias, Universidad de Costa Rica. San José, Costa Rica. Correo electrónico: raguero@cariari.ucr.ac.cr

4 Facultad de Ciencias Agroalimentarias. Universidad de Costa Rica. San José Costa Rica. 
manejo y permite variar la distancia de siembra, para lo cual se deben considerar otros aspectos como la nutrición, el control de malezas, la deshija, las enfermedades, la presencia de artrópodos benéficos o dañinos y el impacto en la ecología del suelo.

En términos generales se dice que el pejibaye para palmito es de gran rusticidad, lo que le permite adaptarse a una amplia gama de condiciones agroecológicas. A pesar del potencial, algunos aspectos importantes en la producción han sido poco estudiados, tales como el manejo de suelos y la nutrición. También se sabe, que el pejibaye es un cultivo tolerante a la acidez del suelo y muy extractor de nutrimentos, aunque gran parte de los elementos son reciclados en el suelo a través de los residuos vegetales (Molina 2000).

El reciclaje de la biomasa del palmito tiene que ver con la dinámica de los microorganismos del suelo, de los cuales, Blanco y Salas (1996) opinan que presentan interacciones complejas que afectan la fertilidad del suelo y el desarrollo de las plantas.

Con respecto al papel de las malezas, De la Cruz (1997), señala que estas crean a mediano o largo plazo un microclima de diversidad, lo que podría dar mayor estabilidad en el balance biológico de algunos insectos, patógenos y en la dinámica de los nutrimentos. Pero junto con los elementos benéficos anotados, se debe considerar el factor económico negativo a corto plazo. Alan et al. (1995) agregan que las malezas pueden presentar beneficios al ambiente, ya que dan una buena cobertura del suelo que evita la erosión, adicionan materia orgánica, permiten el reciclaje y conservación de los minerales del suelo.

Norris y Kogan (2000) explican que existen relaciones tróficas entre artrópodos y malezas que son directas cuando el insecto plaga o el benéfico se alimenta directamente de la maleza, o son indirectas cuando el artrópodo se alimenta dañando el cultivo e impacta a la maleza por alteración de recursos del ecosistema o a través de las malezas que le sirven como hospederos alternos a los artrópodos benéficos presa.

En pejibaye existe un valioso control natural que debe ser cuidado; para la producción de palmito, el cultivo ha mostrado pocos problemas con insectos debido a que las plantas se cortan en un período de dos años, hay una alta radiación y ausencia de microclimas adecuados (Mexzón 1999).

El objetivo del presente trabajo fue evaluar el efecto de cuatro distancias de siembra y dos estrategias de control de malezas (física y química) sobre las variables químicas y los microorganismos y observar poblaciones de insectos y malezas asociadas, en parcelas de pejibaye sin espinas para palmito.

\section{MATERIALES Y MÉTODOS}

\section{Descripción del área de investigación}

El estudio se realizó entre marzo del 2000 y mayo del 2001, en la Estación Experimental Los Diamantes del Ministerio de Agricultura y Ganadería (MAG), ubicada en Guápiles, cantón Pococí, provincia de Limón; a una altitud de $249 \mathrm{msnm}$, con temperatura mínima promedio de $24{ }^{\circ} \mathrm{C}$ y máxima promedio de $29{ }^{\circ} \mathrm{C}$. La precipitación promedio anual es de $4.500 \mathrm{~mm}$.

\section{Preparación del terreno y siembra}

El terreno se mecanizó con una pasada de arado y dos de rastra y se sembró en marzo del 2000. Se usaron plantas con raíz desnuda de pejibaye sin espinas de la variedad Diamantes 10 , con tres meses de germinadas y dos pares de hojas formadas. La fertilización se hizo siguiendo las instrucciones en el manual de recomendaciones del cultivo (Bogantes 1996).

\section{Tratamientos y diseño experimental}

Los tratamientos evaluados fueron la combinación de cuatro distancias de siembra entre plantas con dos estrategias de manejo de malezas (Cuadro 1).

La estrategia física en las bandas consistió en deshierbas con cuchillo, mientras que en el centro se hicieron dos chapeas con cuchillo y las siguientes con motoguadaña. El control químico se hizo con el herbicida glifosato $(35,6 \mathrm{SL}, 0,9-1,0 \mathrm{~kg}$ i.a./ha y $68 \% \mathrm{SG}, 2,40 \mathrm{~kg}$ i.a./ha) según la densidad y la altura de las malezas en el

Cuadro 1. Arreglo de distancias de siembra y estrategias de control de malezas. Guápiles, Limón, Costa Rica. 2000-2001.

\begin{tabular}{cccl}
\hline $\begin{array}{c}\text { Distancia/ } \\
\text { hilera (m) }\end{array}$ & $\begin{array}{c}\text { Distancia/ } \\
\text { planta (m) }\end{array}$ & $\begin{array}{c}\text { Densidad } \\
\text { (plantas/ha) }\end{array}$ & $\begin{array}{l}\text { Manejo } \\
\text { malezas }\end{array}$ \\
\hline 2,0 & 0,25 & 20.000 & Químico \\
2,0 & 0,50 & 10.000 & Químico \\
2,0 & 0,75 & 6.666 & Químico \\
2,0 & 1,00 & 5.000 & Químico \\
2,0 & 0,25 & 20.000 & Físico \\
2,0 & 0,50 & 10.000 & Físico \\
2,0 & 0,75 & 6.666 & Físico \\
2,0 & 1,0 & 5.000 & Físico \\
\hline
\end{tabular}


momento de la aplicación. Se usó una bomba de mochila marca Field King de 14 litros con una boquilla TJ 8002.

Durante el período de evaluación, se permitió una mayor densidad y altura de malezas en el centro (entrecalle) con respecto a la banda del cultivo. El ancho de la banda fue de 0,25 metros en cada lado de la hilera del cultivo y en el centro de 1,5 m. La altura de las malezas en la banda no sobrepasó los 20 centímetros durante las primeras seis semanas de control, ni los 35 centímetros durante el resto de la evaluación, mientras que en la entrecalle, la altura máxima de las malezas fue de 45 centímetros. En esos períodos la altura promedio de las plantas de palmito fue de $25 \mathrm{~cm}$ para el primero y 50 $\mathrm{cm}$ para el segundo.

Se usó un diseño de parcelas divididas distribuidas en cuatro bloques al azar. La estrategia de manejo de malezas se asignó a la parcela grande y las distancias de siembra entre plantas a la pequeña, para un total de 32 parcelas. Cada parcela pequeña midió $64 \mathrm{~m}^{2}$ y se usó una área útil de $48 \mathrm{~m}^{2}$.

\section{Variables evaluadas}

\section{1) Características químicas del suelo}

Se hizo un muestreo para análisis químico del suelo, un mes después de la siembra (1mds) y otro a los 13 mds. El muestreo se hizo con palín en las entrecalles a $20 \mathrm{~cm}$ de profundidad, con una muestra por bloque en el primer muestreo y una muestra por tratamiento para el segundo, ambas, compuestas por cuatro submuestras. Las muestras fueron procesadas en el laboratorio de suelos del Ministerio de Agricultura y Ganadería (MAG) para su análisis químico.

\section{2) Microorganismos en el suelo}

Se hicieron dos muestreos, el inicial 15 días después de la siembra (15 dds) y el segundo a los 13 mds. El muestreo se hizo con palín en las entrecalles a $15 \mathrm{~cm}$ de profundidad, con una muestra compuesta por cuatro submuestras. Las muestras fueron procesadas en el laboratorio de fitopatología del MAG para la determinación del número de unidades formadoras de colonias (UFC) de hongos, bacterias y actinomicetes.

El análisis estadístico de las variables se hizo con el programa SAS. Para la variable microorganismos en el suelo, los datos del ANDEVA se transformaron a logaritmo de x. Para separar la diferencia entre medias se usó Duncan al 5\%.

\section{3) Insectos y malezas asociadas}

Ambos muestreos (insectos y malezas) se hicieron en un bloque adicional de cuatro parcelas con las mismas dimensiones $\left(64 \mathrm{~m}^{2}\right)$ con plantas de palmito de la misma edad y sembradas también a cuatro distancias entre plantas $(0,25 ; 0,5 ; 0,75$ y $1 \mathrm{~m})$ que se dejaron a libre competencia con las malezas.

Se evaluaron los insectos presentes a los tres y 14 meses después de la siembra (mds). Se hicieron capturas con una red entomológica de golpe $(30 \mathrm{~cm}$ de diámetro), con la cual se caminó en zig zag a lo ancho de la parcela $(8 \mathrm{~m})$ y a la altura de las malezas $(1,20$ a 1,30 $m$ en ambos muestreos). Además, se evaluaron las especies de malezas presentes en cada muestreo de insectos. Se usó un marco de hierro 0,5 x 0,5 m lanzado dos veces en cada parcela. Se estimó en forma visual, la cobertura en $\%$ por especie.

Para el análisis de los insectos y malezas se sacó el promedios de dos observaciones o muestreos por parcela. También se calculó un índice de biodiversidad por tratamiento que consiste en dividir el número de especies (n) sobre el total de individuos (N) o sea $\mathrm{n} / \mathrm{N}$ (Odum y Sarmiento 1997).

\section{RESULTADOS}

\section{Características químicas del suelo}

En los Cuadros 2 y 3, se observan los resultados del análisis químico al inicio y al final del estudio (13 mds).

\section{1) $\mathrm{pH}$ y Al intercambiable}

A los 13 mds no hubo diferencias entre distancias ( $p \leq 0,61)$ con respecto al $\mathrm{pH}$ en el suelo de las parcelas; tampoco entre estrategias ( $\mathrm{p} \leq 0,13)$, no obstante, se observó un leve aumento del pH en las parcelas tratadas con combate físico. En general, el promedio inicial del pH $(4,88)$ aumentó a alrededor de 5,20 en el segundo muestreo.

El Al intercambiable bajó de 0,38 en el primer muestreo a 0,31 o menos en el segundo. En este segundo 
Cuadro 2. Valores en el suelo de $\mathrm{pH}, \mathrm{Al}$, bases (cmol/l); P, $\mathrm{Zn}, \mathrm{Mn}(\mathrm{mg} / \mathrm{l}) ; \mathrm{M} . \mathrm{O}$. y N (\%) en el primer muestreo, en pejibaye para palmito. Promedio general y por bloques. Guápiles, Limón, Costa Rica. 2000-2001.

\begin{tabular}{lcccccccccc}
\hline Bloque & $\mathbf{p H}$ & $\mathbf{A l}$ & $\mathbf{C a}$ & $\mathbf{M g}$ & $\mathbf{K}$ & $\mathbf{P}$ & $\mathbf{Z n}$ & $\mathbf{M n}$ & M.O. & $\mathbf{N}$ \\
\hline Bloque 1 & 4,90 & 0,40 & 8,20 & 2,30 & 0,40 & 5,70 & 1,50 & 37,70 & 5,30 & 0,20 \\
Bloque 2 & 4,90 & 0,30 & 6,70 & 2,20 & 0,40 & 6,70 & 1,50 & 36,70 & 5,60 & 0,20 \\
Bloque 3 & 4,80 & 0,40 & 6,50 & 2,40 & 0,40 & 4,70 & 1,10 & 38,00 & 5,00 & 0,20 \\
Bloque 4 & 4,90 & 0,40 & 6,30 & 2,30 & 0,20 & 4,30 & 0,90 & 20,70 & 5,40 & 0,20 \\
Promedio & $\mathbf{4 , 8 7}$ & $\mathbf{0 , 3 8}$ & $\mathbf{6 , 9 2}$ & $\mathbf{2 , 3 0}$ & $\mathbf{0 , 3 5}$ & $\mathbf{5 , 3 5}$ & $\mathbf{1 , 2 5}$ & $\mathbf{3 3 , 2 8}$ & $\mathbf{5 , 3 2}$ & $\mathbf{0 , 2 0}$ \\
\hline
\end{tabular}

Cuadro 3. Valores en suelo de $\mathrm{pH}, \mathrm{Al}$, bases (cmol/l); P, Zn, Mn (mg/l); M.O. y N (\%) según distancia de siembra y estrategia de control de malezas, en el segundo muestreo (13 mds), en pejibaye para palmito. Guápiles, Limón, Costa Rica. 2000-2001.

\begin{tabular}{|c|c|c|c|c|c|c|c|c|c|c|}
\hline $\begin{array}{c}\text { Distancia } \\
\text { (m) }\end{array}$ & $\begin{array}{l}\text { pH } \\
\text { n.s. }\end{array}$ & $\begin{array}{l}\text { Al } \\
\text { n.s }\end{array}$ & $\begin{array}{l}\text { Ca } \\
\text { n.s }\end{array}$ & $\begin{array}{l}\text { Mg } \\
\text { n.s }\end{array}$ & $\mathbf{K}$ & $\begin{array}{c}\text { P } \\
\text { n.s }\end{array}$ & $\begin{array}{l}\text { Zn } \\
\text { n.s }\end{array}$ & $\begin{array}{c}\text { Mn } \\
\text { n.s }\end{array}$ & $\begin{array}{c}\text { M.O. } \\
(p \leq 0,05)\end{array}$ & $\begin{array}{c}\mathbf{N} \\
\text { n.s }\end{array}$ \\
\hline 0,25 & 5,25 & 0,34 & 3,25 & 1,19 & 0,54 & 2,25 & 1,19 & 13,88 & 5,22 & 0,15 \\
\hline 0,50 & 5,26 & 0,32 & 3,51 & 1,25 & 0,57 & 2,25 & 0,99 & 12,88 & 5,41 & 0,17 \\
\hline 0,75 & 5,27 & 0,31 & 3,41 & 1,16 & 0,48 & 2,25 & 0,96 & 13,00 & 5,48 & 0,17 \\
\hline 1,00 & 5,21 & 0,32 & 3,34 & 1,14 & 0,51 & 2,00 & 0,96 & 12,12 & 5,46 & 0,16 \\
\hline Estrategia & & $(\mathrm{p} \leq 0,02)$ & & & $\leq 0,0$ & & & & & \\
\hline Física & 5,30 & 0,30 & 3,49 & 1,22 & 0,66 & 2,37 & 1,03 & 13,62 & 5,38 & 0,16 \\
\hline Química & 5,19 & 0,34 & 3,26 & 1,14 & 0,38 & 2,00 & 1,01 & 12,31 & 5,40 & 0,17 \\
\hline
\end{tabular}

muestreo el $\mathrm{Al}$ intercambiable fue menor en el suelo de las parcelas con control físico de malezas $(\mathrm{p} \leq 0,02)$ y no hubo diferencias entre distancias $(\mathrm{p} \leq 0,60)$.

\section{2) Bases $\mathrm{Ca}, \mathrm{Mg}, \mathrm{K}$}

En el segundo muestreo (13 mds) los valores de Ca y $\mathrm{Mg}$, no fueron diferentes entre distancias ( $\mathrm{p} \leq$ $0,58$ y 0,68$)$ ni entre estrategias de control de malezas ( $\mathrm{p} \leq 0,58$ y 0,62 respectivamente). Con respecto al $\mathrm{K}$, no hubo diferencias entre distancias $(\mathrm{p} \leq 0,30)$ pero si entre estrategias $(\mathrm{p} \leq 0,04)$, con cantidades más altas en las parcelas con tratamiento físico. Los valores de $\mathrm{Ca}$, disminuyeron en forma importante en todos los tratamientos con respecto al primer muestreo.

\section{3) $P$, Zn y $M n$}

La cantidad de $\mathrm{P}$ en el segundo muestreo, no fue diferente entre distancias $(\mathrm{p} \leq 0,41)$ ni entre estrategias ( $\mathrm{p} \leq 0,39$ ), aunque si se observó una disminución importante de este elemento con respecto al primer muestreo. Las cantidades de $\mathrm{Zn}$ y Mn a los 13 meses del estudio, fueron similares tanto entre distancias $(\mathrm{p} \leq 0,29$ y 0,72 ) como entre estrategias ( $p \leq 0,90$ y 0,45 ). Las cantidades de $\mathrm{Mn}$ fueron inferiores en el segundo muestreo.

\section{4) N y Materia orgánica (M.O.)}

En general, hubo una leve disminución del $\mathrm{N}$ en el suelo a los 13 meses del estudio. No obstante, en ese segundo muestreo, el $\mathrm{N}$ en el suelo no fue diferente entre distancias de siembra $(p \leq 0,18)$ ni entre estrategias de combate de malezas ( $\mathrm{p} \leq 0,48)$. Con respecto a las cantidades de materia orgánica en el suelo (MO) 13 mds, estas fueron similares entre estrategias de control ( $\mathrm{p} \leq$ $0,82)$ y aumentaron conforme aumentó la distancia hasta $0,75 \mathrm{~m}$ y luego disminuyó ( $\mathrm{p} \leq 0,05$ ).

\section{Microorganismos en el suelo}

En todos los tratamientos las cantidades de UFC de hongos, bacterias y actinos en el suelo, fueron superiores en el segundo muestreo (Cuadro 4). En el primer muestreo ( $15 \mathrm{dds})$ no se dieron diferencias entre distancias $(\mathrm{p} \leq 0,26)$ ni entre estrategias de combate $(\mathrm{p}$ $\leq 0,74)$ con respecto a la cantidad de UFC de hongos. 
Cuadro 4. Promedio de unidades formadoras de colonias de hongos, bacterias y actinos según la distancia y estrategia de control de malezas en palmito al inicio y al final del estudio. Guápiles, Limón, Costa Rica. 2000-2001.

\begin{tabular}{crrrrrr}
\hline \multirow{2}{*}{$\begin{array}{c}\text { Distancia } \\
(\mathbf{m})\end{array}$} & \multicolumn{2}{c}{ Hongos } & \multicolumn{2}{c}{ Bacterias } & \multicolumn{2}{c}{ Actinos } \\
\cline { 2 - 7 } & \multicolumn{2}{c}{ UFC x 10 E5 } & \multicolumn{2}{c}{ UFC x 10 E6 } & \multicolumn{2}{c}{ UFC x 10 E6 } \\
& Inicio & Final & Inicio & Final & Inicio & Final \\
& & & & & & \\
\hline 0,25 & 10,58 & 13,19 & 25,00 & 119,01 & 31,13 & 146,13 \\
0,50 & 11,93 & 16,50 & 26,68 & 118,15 & 27,54 & 119,30 \\
0,75 & 11,12 & 11,77 & 24,46 & 54,99 & 30,80 & 72,31 \\
1,00 & 6,39 & 13,41 & 20,73 & 83,71 & 20,21 & 89,11 \\
Estrategia & & & & & & \\
Físico & 11,02 & 17,32 & 20,74 & 119,39 & 28,83 & 125,32 \\
Química & 9,00 & 10,11 & 27,69 & 68,54 & 26,01 & 88,11 \\
& $(\mathrm{p} \leq 0,02)$ & & & & \\
\hline
\end{tabular}

Para el segundo muestreo (13 mds) las cantidades de UFC de hongos fueron más altas en las parcelas con combate físico con respecto al químico $(\mathrm{p} \leq 0,02)$ y se dio un aumento leve a 0,50 m para luego disminuir conforme aumentó más la distancia de siembra $(\mathrm{p} \leq 0,97)$.

Las poblaciones de bacterias en el primer muestreo fueron iguales entre distancias $(\mathrm{p} \leq 0,63)$ y también similares entre estrategias de control $(\mathrm{p} \leq 0,08)$. En el segundo muestreo las cantidades de UFC tendieron a disminuir conforme aumentó la distancia de siembra. También se dieron poblaciones más altas en las parcelas tratadas con combate físico.

En el caso de actinomicetes, las poblaciones en el primer muestreo fueron parecidas entre distancias ( $\mathrm{p} \leq$ $0,26)$ y entre estrategias ( $p \leq 0,94)$, mientras que en el segundo muestreo también se dio una tendencia a la disminución conforme aumentó la distancia de siembra. Cantidades más altas de actinomicetes se dieron en las parcelas tratadas con combate físico.

\section{Insectos y vegetación acompañante}

Se capturaron un total de 65 familias de insectos, asociados a las malezas presentes en todas las parcelas (del bloque adicional) durante los dos muestreos efectuados.

Las principales familias de insectos al inicio de la prueba (3 mds) fueron Aphididae, Braconidae, Cicadellidae, Coreidae, Chrysomelidae, Carabidae, Cixiidae, Dolichopodidae, Curculionidae, Locustidae. Lygaeidae, Miridae, Nabidae, Pentatomidae y Tettigoniidae. Para el segundo muestreo, al final de la prueba, las principales familias fueron: Braconidae, Cixiidae, Carabidae, Cicadellidae, Chrysomellidae, Curculionidae, Dolichopodidae, Eucharitidae, Locustidae, Lygaeidae, Miridae, Nabidae, Noctuidae, Pentatomidae, Tettigoniidae y Reduviidae.

Con respecto a las distancias de siembra entre plantas, el mayor incremento en el número de familias, morfoespecies y número de individuos se dio en las parcelas sembradas a $0,25 \mathrm{~m}$, mientras que el efecto contrario se observó en las parcelas sembradas a mayor distancia entre plantas. Si se considera la biodiversidad, fue superior en las parcelas a $0,25 \mathrm{~m}$ y similar entre las otras distancias sobre todo al inicio del estudio (Cuadro 5).

Según el listado de malezas presentes en donde se hicieron los muestreos de insectos, la cobertura de especies de hoja ancha fue superior en el primer muestreo (3 mds) y se observó mayor cobertura de poáceas durante

Cuadro 5. Número de familias, morfoespecies e individuos de insectos según distancia de siembra en palmito de pejibaye al inicio y final de la prueba. Guápiles, Limón, Costa Rica. 2000-2001.

\begin{tabular}{ccccccccc}
\hline $\begin{array}{c}\text { Distancia } \\
(\mathbf{m})\end{array}$ & \# familias & \multicolumn{3}{c}{$\begin{array}{c}\text { morfoespecies } \\
(\mathbf{n})\end{array}$} & $\begin{array}{c}\text { \# individuos } \\
(\mathbf{N})\end{array}$ & \multicolumn{2}{c}{$\begin{array}{c}\text { Biodiversidad } \\
(\mathbf{n} / \mathbf{N})\end{array}$} \\
\cline { 2 - 9 } & \multicolumn{1}{c}{ Inicio } & Final & Inicio & Final & Inicio & Final & Inicio & Final \\
\hline & & & & & & & & \\
0,25 & 15 & 19 & 21 & 26 & 34 & 53 & 0,62 & 0,49 \\
0,50 & 19 & 20 & 32 & 31 & 84 & 84 & 0,38 & 0,37 \\
0,75 & 15 & 20 & 26 & 26 & 59 & 78 & 0,44 & 0,33 \\
1,00 & 17 & 19 & 26 & 24 & 61 & 48 & 0,43 & 0,50 \\
Total* & 43 & 53 & & & & & & \\
\hline
\end{tabular}

* Total de familias en todas las parcelas. 
el segundo muestreo, sin grandes diferencias entre distancias de siembra. Las especies de ciperáceas aparecen en el segundo muestreo con una cobertura baja en las parcelas sembradas a 0,$25 ; 0,75$ y $1 \mathrm{~m}$ (Cuadro 6).

Cuadro 6. Porcentaje de cobertura por grupos de malezas, según distancia de siembra, en los muestreos de insectos en palmito de pejibaye al inicio y final del estudio. Guápiles, Limón, Costa Rica. 2000-2001.

\begin{tabular}{ccccccc}
\hline \multirow{2}{*}{$\begin{array}{c}\text { Distancia } \\
(\mathbf{m})\end{array}$} & \multicolumn{2}{c}{ Poáceas } & \multicolumn{2}{c}{ Ciperáceas } & \multicolumn{2}{c}{ Hoja ancha } \\
\cline { 2 - 7 } & Inicio & Final & Inicio & Final & Inicio & Final \\
\hline 0,25 & 25 & 96 & 0 & 1 & 75 & 3 \\
0,50 & 23 & 74 & 0 & 0 & 77 & 13 \\
0,75 & 24 & 71 & 0 & 11 & 76 & 3 \\
1,00 & 26 & 90 & 0 & 1 & 74 & 9 \\
\hline
\end{tabular}

Con respecto a la cobertura de las especies de poáceas, sobresalió Paspalum fasciculatum tanto en el primero ( $12 \%$ ) como en el segundo muestreo (76\%); mientras que en las hojas anchas prevalecieron especies como Ageratum conyzoides y Sida spp con coberturas importantes en el primer muestreo ( $20 \%$ y $30 \%$ respectivamente). Las especies, disminuyeron en todos los tratamientos en el segundo muestreo (Cuadro 7). Debe recordarse que este estudio se hizo en parcelas de palmito a libre competencia de malezas lo cual no es lo común en el cultivo.

\section{DISCUSIÓN}

\section{Características químicas del suelo}

Según Molina (2000) las características de fertilidad de los suelos que tienen mayor importancia en la nutrición del cultivo son el $\mathrm{pH}$, la acidez intercambiable, el contenido de $\mathrm{Ca}, \mathrm{Mg}$ y la capacidad de intercambio catiónico efectiva (CICE). En este estudio no se originaron grandes diferencias entre tratamientos con respecto a los nutrimentos del suelo ; una ligera excepción en el segundo muestreo (13 mds) lo constituyeron pequeñas diferencias de bases entre estrategias, en especial una mayor cantidad de $\mathrm{K}$ en las parcelas con combate físico, atribuibles a menos pérdida por percolación o escorrentía por la presencia casi constante de una cobertura de $P$. fasciculatum (gamalote).

Aunque el primer muestreo de suelos se hizo por bloques, los promedios son útiles para determinar algu-
Cuadro 7. Lista de especies de malezas y su cobertura promedio en las parcelas de muestreo de insectos al inicio y final de la prueba en pejibaye para palmito. Guápiles, Limón, Costa Rica. 2000-2001.

\begin{tabular}{|c|c|c|c|}
\hline \multirow[t]{2}{*}{ Familia } & \multirow[t]{2}{*}{ Especie } & \multicolumn{2}{|c|}{ bertura promedio* } \\
\hline & & Inicio & Final \\
\hline Asteraceae & Ageratum conyzoides L. & 20 & 0,13 \\
\hline Asteraceae & Jaegeria hirta (Lag.) Less. & 1 & 0 \\
\hline Conmelinaceae & Commelina difusa Burm f. & 0 & 0,13 \\
\hline Cyperaceae & Cyperus ferax L.C. Rich. & 0 & 1 \\
\hline Euphorbiaceae & Acalypha alopecuroides Jacq. & 3 & 1 \\
\hline Euphorbiaceae & Phyllanthus niruri L. & 0 & 0,25 \\
\hline \multirow[t]{2}{*}{ Leguminosae } & Senna obtusifolia (L.) Irwin & & \\
\hline & \& Barneby & 1 & 0 \\
\hline Leguminosae & Mimosa pudica $\mathrm{L}$. & 3 & 0,38 \\
\hline Malvaceae & Sida acuta Burm f. & 20 & 7 \\
\hline Malvaceae & Sida rhombifolia $\mathrm{L}$. & 10 & 0 \\
\hline Oxalidaceae & Oxalis barrealeri $\mathrm{L}$. & 8 & 0 \\
\hline Poaceae & Cenchrus sp. & 0 & 0,13 \\
\hline \multirow[t]{2}{*}{ Poaceae } & Digitaria sanguinalis (L.) & & \\
\hline & Scop. & 6 & 3 \\
\hline Poaceae & Eleusine indica (L.) Gaertn. & 0,31 & 0,31 \\
\hline Poaceae & Homolepsis sp. & 0 & 4 \\
\hline \multirow[t]{2}{*}{ Poaceae } & Paspalum fasciculatum & & \\
\hline & Willd. ex Flüggé & 12 & 76 \\
\hline \multirow[t]{2}{*}{ Poaceae } & Rottboellia cochinchinensis & & \\
\hline & (Lour.) Clayton & 6 & 0,13 \\
\hline Rubiaceae & Spermacoce laevis L. & 3 & 0,13 \\
\hline Solanaceae & Physalis angulata $\mathrm{L}$. & 4 & 0 \\
\hline Verbenaceae & $\begin{array}{l}\text { Stachytarpheta cayennensis } \\
\text { (Rich.) Vahl }\end{array}$ & 3 & 1 \\
\hline
\end{tabular}

* Promedio de todas las parcelas.

nos cambios a los 13 mds, como el aumento promedio del pH en más de 0,40 unidades, una respuesta ya esperada a la enmienda hecha con cal dolomítica en todo el experimento y al aporte del fertilizante Nitramón utilizado, lo cual también podría explicar la leve disminución del Al. No obstante, cambios más importantes en el pH (hasta dos unidades) se obtienen en mayor tiempo y con altas cantidades de $\mathrm{CaO}$ (2,8 t/ha) (Fassbender 1986).

Según Herrera (1989) la extracción de nutrientes del suelo por el cultivo de palmito es importante y el orden es: $\mathrm{N}>\mathrm{K}>\mathrm{Ca}>\mathrm{Mg}>\mathrm{P}>\mathrm{Mn}>\mathrm{Fe}>\mathrm{Zn}$, la mayor parte son removidos por la biomasa vegetativa. $\mathrm{Fe}$ rrufino (2001) hace énfasis en la exportación y acumulación de $\mathrm{N}$ y K en la biomasa de plantas de palmito; estas consideraciones podrían explicar menores cantidades promedio de esos nutrimentos determinadas en el segundo muestreo; adicionalmente, hay fertilizante 
que se pierde por lixiviación o escorrentía. El fósforo es otro elemento, requerido por la planta en sus primeros meses, para el desarrollo de raíces.

Además, con tan sólo dos meses de iniciada la cosecha de las primeras plantas en las parcelas, el reciclaje esperado de nutrimentos al suelo, hasta $84 \%$, según Molina y colaboradores (citados por Soto et al. 2002) no estaría disponible en el suelo a muy corto plazo, ya que es un proceso de liberación parcial y acumulativo en el tiempo.

En el caso particular del $\mathrm{Ca}$, las altas cantidades del primer muestreo podrían estar influenciadas por menor humedad en el suelo, debido al período seco en que se hizo el muestreo (abril), con una precipitación acumulada de sólo $46 \mathrm{~mm}$. En ese sentido Berstch $(2002)^{5}$ comenta que en condiciones de menor humedad en el suelo el Ca se concentra.

Con respecto a la materia orgánica el cultivo intensivo de palmito incrementa progresivamente su contenido en el suelo debido a la constante renovación de hojas y descomposición de residuos de cosecha; sin embargo, hasta el segundo muestreo su aumento fue leve con respecto al primer muestreo, tal vez por el corto período de cosecha (dos meses) realizada hasta esa fecha. Otros trabajos relacionados con el aporte de MO producto de enmiendas o en sistemas agroforestales, tampoco observaron grandes cambios de $\mathrm{MO}$ en el corto plazo (Leal et al. 2000).

A partir de los seis meses la cobertura de malezas disminuyó conforme a la disminución en la distancia de siembra; por lo tanto, menos aporte de biomasa de las malezas en esas parcelas, también pudo incidir en una leve disminución del contenido de MO.

\section{Microorganismos en el suelo}

Fueron evidentes mayores poblaciones de hongos, bacterias y actinos en el segundo muestreo a pesar del poco tiempo, con respecto al segundo (13 mdds). Las bajas cantidades de UFC de microorganismos en el primer muestreo con respecto al segundo podrían estar influenciadas por factores como la mecanización hecha para la siembra, la baja precipitación en la época del muestreo, pH más bajo, que pudo haber afectado principalmente la actividad de bacterias y actinomicetes (Fassbender 1986). Además, poca biomasa de malezas o residuos de cosecha, incorporados en la época del estudio.

\footnotetext{
5 BERSTCH, F. 2002. Efecto de la humedad del suelo en la concentración del Ca. San José, Costa Rica. Universidad de Costa Rica. Entrevista.
}

Ramírez (1996) opina que las prácticas de manejo afectan la actividad de los microorganismos de una manera directa al alterar las condiciones físicas y químicas, tales como temperatura del suelo, humedad, aireación, estado de oxireducción, contenido y composición de gases del espacio poroso y accesibilidad a sustratos, Esquivel (1996) menciona que la temperatura del suelo varía con la profundidad y período del año; la fluctuación es mayor en los primeros $15 \mathrm{~cm}$; y es una variable física que tiene gran significado biológico y puede afectar diversas actividades.

En el caso de los hongos, según Kurle y Pfleger (citados por Blanco y Salas 1996) el efecto más importante de la labranza del suelo en su funcionamiento tiene que ver con el resquebrajamiento de la red de micelio extraradical.

Además de la humedad del suelo y la temperatura, la actividad microbiana depende mucho más de la disponibilidad de $\mathrm{C}$ fácilmente accesible que es utilizado como fuente de energía (Espinoza 1996); en ese sentido, mayores poblaciones de hongos, bacterias y actinos determinadas en el suelo de las parcelas sembradas a 0,25 y $0,50 \mathrm{~m}$ en el segundo muestreo, podría estar influenciada por el efecto de las raíces y la biomasa de las primeras plantas cosechadas, cuya cantidad fue superior en esas parcelas (con mayor densidad de palmito), lo cual se convirtió en un buen sustrato para los microorganismos.

Con respecto al aumento general de UFC de microorganismos en las parcelas con combate físico de malezas durante el segundo muestreo, se podría relacionar con la mayor cobertura de malezas, principalmente $P$. fasciculatum la cual prevaleció en los centros y sirvió como sustrato o favoreció el medio con más humedad en el suelo . No es claro un efecto directo del herbicida sobre esos microorganismos.

\section{Insectos en vegetación acompañante}

En general, si se considera el número y tamaño de las parcelas, así como los períodos de libre competencia entre cultivo y malezas, en el área del muestreo de insectos, se podría afirmar que la cantidad de familias, especies y número de individuos da información importante a pesar de que solo se hicieron dos muestreos y el segundo fue a los 14 mds. Estudios más sistemáticos y contínuos en el tiempo han documentado una gran cantidad de especies de artrópodos (203) en pejibaye para fruta (Mexzón 1997 a, b).

Se podría inferir sobre una interesante afinidad entre insectos y malezas en cada muestreo. En el caso de 
las familias Aphididae, Cicadellidae, Chrysomelidae, Curculionidae, Locustidae, Tettigoniidae y Nabidae, son artrópodos afines al $P$. fasciculatum que aumentaron (casi todas las familias) conforme aumentó la cobertura de dicha maleza en el segundo muestreo; $P$. fasciculatum sirvió como refugio y sitio de alimento. En ese sentido, Mexzón (1999) comenta, que plantas de follaje denso sostienen un mayor número de especies de insectos que las plantas de follaje escaso o con hojas pequeñas.

Familias como Locustidae, Tettigonidae y Cicadellide, tienden a incrementar en zacates para el camuflaje de sus ninfas. En el caso particular de la familia Cicadellidae con alta incidencia en ambos muestreos, otros estudios, informan algunas especies muestreadas en malezas de pejibaye, pero que atacan follaje del cultivo y pueden producir entrada del hongo Pestalotiopsis sp. (Mexzón 1999). Además, la alta incidencia de insectos de esa familia, probablemente atrajo a insectos de otras familias como Nabidae y Reduviidae que son depredadores y utilizan zacates para el camuflaje; los primeros se comen sus ninfas y las de locústidos; también, los cicadélidos secretan ligamaza una sustancia de los homópteros que atrae parasitoides como los de las familias Chalcididae, Eucharitidae, Eulophidae, Pteromalidae y Scelionidae, los cuales se refugiaron principalmente en la especie $A$. conyzoides.

En el caso de los escarabajos Chrysomelidae y Curculionidae, sus larvas permanecen en zacates donde se alimentan de sus raíces y endurecen el tegumento para luego emerger como adultos. En esa etapa de adultos, cuando recién han emergido del suelo, es cuando los Reduviidae aprovechan para depredarlos (Mexzón 2002) 6 .

En ese sentido, se afirma que la flora acompañante de los cultivos puede albergar insectos plaga, patógenos y sus vectores pero también sostienen entomofauna benéfica tales como fitófagos neutrales, depredadores y parasitoides (Mexzón y Chinchilla 1999).

Otras familias de insectos como Braconidae, Coreidae, Carabidae, Drosophilidae y Dolichopodidae, son más atraídos por la maleza A. conyzoides, cuya cobertura fue abundante en el primer muestreo y baja en el segundo.También se podría relacionar en ambos muestreos, la presencia de las familias Lygaeidae y Pentatomidae afines a las especies de malezas $S$. acuta y $S$. rhombifolia. Algunos géneros de estas familias son más afines a plantas del tipo malváceas.
El aumento de familias, especies e individuos observado en el segundo muestreo principalmente en las parcelas sembradas a $0,25 \mathrm{~cm}$, aún en términos relativos (índice de biodiversidad, según Odum y Sarmiento (1997)), se podría explicar por la alta densidad y el crecimiento de las plantas de palmito y malezas, principalmente $P$. fasciculatum que permitieron un mejor refugio y área de tránsito para los insectos. En el caso de P. fasciculatum si se etiola debido a la competencia con el cultivo, podría proveer de tejido más tierno para chupadores o masticadores, un efecto contrario podría explicar la disminución de artrópodos en las parcelas sembradas a $1 \mathrm{~m}$ entre plantas.

En ese sentido, Norris y Kogan (2000) señalan que el crecimiento de un cultivo y la presencia de plantas, modifica de inmediato el ambiente, el grado de modificación depende de la cantidad de vegetación presente, la cual a menudo es relacionada con la edad y en menor grado a la cualitativa naturaleza de las especies presentes y afecta a todas las especies de artrópodos.

También, las variaciones climáticas que influyen en la vegetación en esta región, promueven la abundancia de especies de hoja ancha como las asteráceas, euforbiáceas, leguminosas y malváceas en el período menos lluvioso (diciembre-abril), lo cual cambia la dinámica de las poblaciones de insectos. Con el inicio de las lluvias, el cambio de la vegetación a poáceas como P. fasciculatum, favorece las poblaciones de insectos con mayor afinidad a zacates como crisomélidos, curculiónidos y cicadélidos (Mexzón 2002) ${ }^{6}$.

De manera general, hubo efecto de los tratamientos con respecto a algunas características químicas del suelo. Los principales cambios en las cantidades de hongos, bacterias y actinos en el suelo, se dieron entre el primero y segundo muestreo y en la estrategia física.

En el bloque adicional, hubo aumentos importantes entre el primero y segundo muestreo (14 mds) en el número de morfoespecies e individuos en ocho familias de insectos y se encontró afinidad entre familias de insectos con malezas presentes, principalmente la influencia de especies como P. fasciculatum, A. conyzoides y Sida spp. No obstante, el libre crecimiento de las malezas en estas parcelas, no es lo común en una plantación de palmito.

Relaciones más evidentes o concluyentes entre distancias de siembra, malezas e insectos se podrían encontrar con períodos de tiempo más prolongados entre los muestreos.

6 MEXZON, R. 2002. Relaciones entre insectos. San José, Costa Rica. Universidad de Costa Rica. 


\section{LITERATURA CITADA}

ALAN, E.; BARRANTES, U.; SOTO, A.; AGÜERO, R. 1995. Elementos para el manejo de malezas en agroecosistemas tropicales. Instituto Tecnológico de Costa Rica. Cartago, Costa Rica. 223 p.

BLANCO, F.; SALAS, E. 1996. Micorrizas en la agricultura: contexto mundial e investigación realizada en Costa Rica. In: X Congreso Nacional Agronómico y de Recursos Naturales. EUNED. San José, Costa Rica. p. 69-77.

BOGANTES, A. 1996. Recomendaciones para la siembra y manejo de palmito de pejibaye (Bactris gasipaes K.). Estación Experimental Los Diamantes. Universidad de Costa Rica. 12 p.

DE LA CRUZ , R. 1997. Principios sobre competencia y manejo integrado de malezas. EARTH. Costa Rica. 13 p.

ESQUIVEL, A. 1996. Influencia del suelo sobre las poblaciones de nematodos. In: Bertsch, F.; Badilla, W.; Bornemisza, E. eds. X Congreso Nacional Agronómico y de Recursos Naturales. EUNED. San José, Costa Rica. p. $57-62$.

ESPINOZA, J. 1996. Relación entre la fertilización mineral, la materia orgánica y los microorganismos del suelo. In: Bertsch, F.; Badilla, W.; Bornemisza, E. eds. X Congreso Nacional Agronómico y de Recursos Naturales. EUNED. San José, Costa Rica. p. 119-128.

FASSBENDER, W. 1986. Química de suelos. San José, Costa Rica. p. 168-193.

FERRUFINO, A. 2001. Tembe para palmito. In: Proyecto Concade, USAID. ed. Respuesta a la fertilización en los cultivos comerciales más importantes del trópico de Cochabamba. Chapare. p. 28-30.

HERRERA, W. 1989. Fertilización del pejibaye para palmito. Serie técnica Pejibaye. Mora Urpí, J. ed. UCR, San José, Costa Rica. 5-10 p.

LEAL, D.; KASS, D. ; LOK, R. ; KOPSELL, E. ; IBRAIM, M. 2000. Evaluación participativa de alternativas agroforestales para la producción de palmito (Bactris gasipaes K.) en tierras de ladera del Atlántico de Costa Rica. Agroforestería en las Américas 7(26): 8.
MEXZON, R. 1997 a. Manejo integrado de los artrópodos perjudiciales en el cultivo de pejibaye (Bactris gasipaes K.). In: Curso Nacional de palmito de pejibaye. Universidad de Costa Rica. San José, Costa Rica. 9 p.

MEXZON, R. 1997 b. Reconocimiento de los artrópodos perjudiciales en el cultivo de pejibaye (Bactris gasipaes K.) y algunos de sus enemigos naturales. Informe final. Universidad de Costa Rica. San José, Costa Rica. 13 p.

MEXZON, R. 1999. Manejo integrado de los artrópodos perjudiciales. In: Mora, J.; Gainza, J. eds. Palmito de pejibaye (Bactris gasipaes K.) su cultivo e industrialización. EUCR. San José, Costa Rica. p. 138-141.

MEXZON, R.; CHINCHILLA, C. 1999. Especies vegetales atrayentes de la entomofauna benéfica en plantaciones de palma aceitera (Elaeis guineensis) en Costa Rica. ASD Oil Palm Papers. No. 19. 39 p.

MOLINA, E. 2000. Manual de suelos y nutrición de pejibaye para palmito. $1^{\text {a }}$ ed. EUCR. San José, Costa Rica. 42 p.

MORA URPÍ, J.; BOGANTES, A.; ARROYO, C. 1999. Cultivares de pejibaye para palmito. In: Mora, J.; Gainza, J. eds. Palmito de pejibaye (Bactris gasipaes K.). su cultivo e industrialización. EUCR. San José, Costa Rica.

NORRIS, R.; KOGAN, M. 2000. Interactions between weeds, arthropod pests, and their natural enemies in managed ecosystems. Weed Science 48:94-158.

ODUM, P. E.; SARMIENTO, F. 1997. Ecología. El puente entre ciencia y sociedad. México. p. 58-67.

RAMÍREZ, C. 1996. efecto de las prácticas agrícolas sobre la microflora del suelo: oportunidades en la fitoprotección. In: Bertsch, F.; Badilla, W.; Bornemisza, E. eds. X Congreso Nacional Agronómico y de Recursos Naturales. EUNED. San José, Costa Rica. p 81.

SOTO, G.; LUNA, P.; WAGER, M.; SMYTH T.; ALVARADO, A. 2002. Descomposición de residuos de cosecha frescos y liberación de nutrientes en plantaciones de palmito en Costa Rica. In: Taller Internacional sobre diseño de herramientas para la toma de decisiones en el Manejo Integrado de Nutrientes del suelo. C.I.A. UCR. Guápiles, Costa Rica. p. 68-78. 